Bol. Acad. peru. leng. 68. 2020 (303-313)

\title{
El estereotipo de subalternidad en Pequeña Flor
}

\author{
Laura Alejandra Valdivia Uzátegui \\ lavaldivia6@outlook.com
}

Fecha de recepción:

$29 / 03 / 2020$

Fecha de aceptación:

$14 / 09 / 2020$

Hablar de Clarice Lispector significa adentrarnos en este mundo de mujeres que nos comunican, mediante sus acciones, sus deseos de querer librarse del mundo cómodo, protegido y patriarcal en el cual viven, pero del que son protagonistas. El cuento que escogí para el presente ensayo es «La Mujer más pequeña del mundo».

En la década de los 70, Latinoamérica vivía en crisis política y cultural. Quería dejar de tener rasgos europeos o de los conocidos «ismos» para llegar a construir su propia literatura, aquella que se origina con los campesinos, los movimientos estudiantiles, los otros. Tal como Jean Franco afirma:

Los siempre masculinos protagonistas del boom en sus intentos de idear una sociedad económicamente viable libre del control exterior, tropieza con el espectro del excluido (especialmente el femenino), así como con las

https://doi.org/10.46744/bapl.202002.014 
https://doi.org/10.46744/bapl.202002.014

desgraciadas consecuencias de identificar lo humano exclusivamente con el dominio sobre la naturaleza. (2003, p. 18)

Efectivamente, en el libro Decadencia y caída de la ciudad letrada, Franco nos relata que se llevan a cabo procesos políticos y sociales en los que emerge una manera de contar cómo es Latinoamérica desde la narrativa latinoamericana. La literatura se empieza a plagar de individuos periféricos, de aquellos que no eran dignos de ser colocados dentro de la cultura literaria, pero, también, de aquellas realidades cotidianas con sabor a realismo mágico. Según Elena Carrera:

[Lispector] Would not only break the flow of the narration and would create separation, a duality of subject and object, but also be rather out of place in a poetical fiction which tries to break away from academic writing. (1999, p. 91)

Considero que se desarrollan dos procesos en la literatura de Lispector: primero, tratar de reivindicar la literatura latinoamericana, escribir sobre lo autóctono, lo periférico y el discurso no letrado; segundo, dentro de dicha reivindicación, en la cual los escritores latinoamericanos del boom tratan de posicionar al sujeto latinoamericano en escena, Lispector tiene una doble lucha: hacer oír la voz de las mujeres en esta narrativa patriarcal, que a la vez es su propia voz, su propio discurso.

A comienzo de los sesenta, la escritora brasileña Clarice Lispector había sentido ya la presencia de estos personajes marginales que amenazaban el protagonismo de las personas letradas. (Franco, 2003, p. 25)

En Lazos de familia, las mujeres enajenadas exploran sus propios sentimientos. En «La mujer...», no solo me parece que estereotipa y parodia esta dominación de occidente hacia el continente africano respecto de cómo veían los colonizadores a las razas de aquellos que consideraban «inferiores», sino que parodia el rol que han tenido y tienen las mujeres en la sociedad, en todas las sociedades. «Lispector [...] as a mediator who teaches the approach that opens and leaves space for the other» (Carrera, 1999, p. 92). Así como García Márquez, Fuentes o Rulfo, entre otros, dan voz a personajes latinoamericanos, Lispector da 
https://doi.org/10.46744/bapl.202002.014

presencia a sus personajes femeninos que llenan sus cuentos y novelas. «La mujer...» está plagado de estereotipos y roles adscritos no solo a mujeres u hombres, sino a nivel macro, en esta dominación cultural sobre colonizadores y colonizados.

Según Erin Beeghly, un estereotipo «its a universal generalization about a social group» $(2015$, p. 61), que denomina generics y del cual identifica tres tipos: «Majority generics, characteristic generics and striking property generics» (p. 62). Los characteristic generics — relevantes para mi propósitoson definidos como «make claims about typical group members, claims often related to a group function or role. Think about women cook and clean» (p. 62). Para Beeghly, significa que esta generalización o estereotipo no es erróneo, siempre y cuando esté justificado; en este caso, se cumple de cierto modo el concepto de estereotipo, mas no en todas las ocasiones.

El estereotipo de dominado no solo está en Pequeña Flor, quien es el ser dominado por excelencia, sino que también lo es África Ecuatorial, el primer continente en ser conquistado y colonizado. El Congo Central, lugar donde transcurre la historia, es lo que Edward Said llamaría el «Oriente», lugar que necesita ser nombrado por el otro para tener un lugar en el mundo, para ser representado en él. El encuentro entre el explorador y Pequeña Flor es el encuentro entre los dos mundos, lo occidental y lo raro, lo exótico y lo extraño. La selva del Congo, a la cual Marcel Petre se va adentrando «más a las profundidades» (1988, p. 73), es el cuerpo femenino que él va explorando.

Entre mosquitos y árboles tibios de humedad, entre las hojas ricas del verde más perezoso [...]. En los cálidos humores silvestres, que tempranamente maduran las frutas y les dan una casi intolerable dulzura al paladar [...]. Inmediatamente encuentra a Pequeña Flor que estaba «como en una caja dentro de una caja, dentro de una caja [...]. (1988, p. 73)

Palabras como húmeda, calidad, y la imagen de una caja dentro de otra caja dan la sensación de penetrar en este cuerpo vaginal femenino donde Pequeña Flor podría resultar el clítoris. Sin embargo, en contraste a su nombre delicado y femenino, Pequeña Flor resulta ser todo lo contrario al 
estereotipo de feminidad que se puede tener en mente. Mientras que Marcel Petre es el explorador francés, blanco, «cazador y hombre de mundo» en busca de aventuras, en oposición, Flor es una «mujer de cuarenta y cinco centímetros, madura, negra, callada» (1988, p. 73). Es madura, o sea, una persona mayor de edad, y negra, en oposición a las flores que son la representación de la juventud: frescas, de colores vivos.

Pequeña Flor, al no tener voz por ser callada, tiene que ser representada por el narrador o explorador que la describe al mundo exterior. Por todo esto, puedo precisar que no cumple con el ideal o el imaginario de belleza femenina: no es delicada ni tampoco es una belleza exótica, de esas que acostumbraban a describir los exploradores colonizadores en sus diarios. Dentro de su propia tribu de pigmeos, representa el ser propiedad de otro individuo y también el último alimento de la cadena alimenticia. Marcel Petre informa que, a pesar de que es una tribu alejada de toda civilización, mantiene los roles de género marcados, las mujeres viven en los árboles «de donde descienden las mujeres para cocinar maíz, moler mandioca y coger verduras; los hombres para cazar» (1988, p. 74). Los hombres de la tribu mantienen la misma posición de cazador, al igual que Marcel Petre: son hombres que cumplen las mismas funciones dentro de la sociedad.

Para explicar el hecho de que las mujeres, en la mayoría de las sociedades conocidas, están consignadas a posiciones sociales inferiores, es necesario tomar en cuenta la asimetría de posiciones adscritas a cada género en la económica de los intercambios simbólicos. (Marta Lamas, 1999, pp. 162-163)

Esos intercambios simbólicos a los que Lamas se refiere son las mujeres en sí mismas, donde los hombres trabajan como cazadores para aumentar ese capital simbólico que está ligado a un matrimonio, es decir, a una red de parentesco. Las mujeres, de igual forma, deben preservar ese «valor simbólico» cumpliendo ciertos valores relacionados a lo que significa ser femenino (vestirse de una determinada forma, maquillarse, ser suave, delicada y dócil para aumentar el atractivo y ser poseída por un hombre); en el caso de Pequeña Flor, debe cocinar, preparar la mandioca y servir como medio de procreación. "Cuando nace un hijo, casi inmediatamente le es dada la libertad» (Lispector, 1988, p. 74). Esto 
https://doi.org/10.46744/bapl.202002.014

induce a pensar que, efectivamente, las mujeres likualas actúan como una especie de esclavas reproductoras a las que se les da la «libertad» cuando cumplen su función procreadora. Pero esta libertad no es bien aprovechada, ya que, según el narrador, dependen de los hombres likualas para su protección: de lo contrario, pueden ser devoradas por los bantús que los cazan. «Pero [...] no se lamentaran que para tan corta vida, largo haya sido el trabajo» (p. 74). Clarice nos envuelve en un halo fatalista y conformista a la vez, en el que la corta vida de las mujeres de la tribu «vale la pena» por el trabajo de cocer, cocinar, dar a luz. Estas actividades han superado su corta vida.

El explorador representa aquello que nombra y clasifica, cumple la función de un científico. Eso significa que su conducta debe ir de acuerdo a la razón, es un ser racional. «Seguramente, por no tratarse de un loco, su alma no desvarió ni perdió los limites. Sintiendo una inmediata necesidad de orden, y de dar nombre a lo que existe, le dio el apodo de pequeña Flor» (p. 74). Este pasaje me remite a las palabras que Edward Said tiene respecto a una anécdota en donde Flaubert se encuentra con una cortesana egipcia y lo que dice de ella es el modelo de lo que occidente tomaría de oriente.

«Él hablaría por ella y la representaba. Él era extranjero [...] y esos eran unos factores históricos de dominación que le permitían, no solo poseer a Kuchuk Hanem físicamente, sino hablar por ella [...]. (p. 24)

A Pequeña Flor se le clasifica dentro de la visión occidentalizada en cuatro categorías: animal (perro, mono), cosa (juguete, muñeca), empleada y ser triste. Estas características las iré analizando poco a poco.

Marcel Petre la da a conocer al mundo a través de la ideología, prejuicios y saberes occidentales que él tiene, respecto a lo que él considera que es el «Otro». "Y para conseguir clasificarla entre las realidades reconocibles, de inmediato comenzó a recoger datos sobre ella» (Lispector, 1988, p. 74; cursiva mía). Pequeña Flor cumple la función de objeto clasificable. Es interesante notar cómo Lispector lleva al extremo de la parodia lo que es ser conquistado: desencializa la naturaleza humana de 
la likuala para catalogarla como un «ejemplar» como si fuese un animal extraño. El cazador nombra como si fuera un dios.

Como se señaló antes, a Flor se le da un nombre frágil, reforzado con el adjetivo Pequeña a lo largo de toda la narración. El explorador le atribuye valores femeninos, delicados, y ella responde rascándose las partes íntimas: una representación de un acto grosero no digno de los valores femeninos que debe tener una mujer, lo que coloca al explorador, hombre de mundo, en una posición incómoda. A Pequeña Flor se le califica como un mono que vive en los árboles y representa la involución del hombre; también, como un perro: «Envuelta en un paño, con la barriga en estado adelantado. La nariz chata, la cara negra, los ojos hondos, los pies planos. Parecía un perrito» (p. 75). De nuevo, se le describe con adjetivos poco femeninos y además en diminutivo. El perro puede simbolizar lo leal, el compañero fiel de un hombre, pero según Chevalier, «el perro es el signo del apetito sensual, de la sexualidad, al mismo tiempo que los celos» (1986, p. 820). Pequeña Flor suscita celos en una niña que nota que hay otra persona mucho más pequeña que ella, lo que la hace dejar de poseer aquella denominación y, por tanto, eso que la hace única. Pero, más adelante, vemos que Pequeña Flor suscita también sentimientos de un amor sexual y lujurioso en otros personajes femeninos, esto relacionado al apetito de poseer. El estar desnuda, solo con su paño, puede despertar sentimientos reprimidos de lujuria en otros personajes pudorosos, ya que la desnudez femenina representa el despertar de los instintos sensuales que se han escrito en la literatura desde la literatura romántica.

La imagen de Pequeña Flor aparece en el periódico. Ella es vista por varias personas (en especial, mujeres) que tienen diversas opiniones sobre ella, pero que no dejan de posicionarla en un estado inferior respecto de sí mismas o de cualquier otro ser. El ser pequeña suscita sentimientos de protección, maternales, pero las mujeres que la ven sienten pena y compasión por esta característica, lo que se resalta en la primera mujer que ve el diario. Lispector explora, a la vez, los sentimientos de las mujeres. Flor es pequeñita $y$, de acuerdo con sus características, tiene rasgos animales, lo que suscita sentimientos de ternura, pero a la vez el querer aprovecharse de ella, como la segunda señora: 
https://doi.org/10.46744/bapl.202002.014

Una señora tuvo tal perversa ternura por la pequeñez de la mujercita africana que $[\ldots]$, jamás se debería dejar a Pequeña Flor a solas con la ternura de tal señora. iQuién sabe a qué oscuridades de amor puede llegar el cariño! (p. 76)

Por un lado, se observa el amor lujurioso de poseer algo, situación que sucede con otros personajes; por otro, se recalca de nuevo la pequeñez de Flor a través de la frase "pequeñez de la mujercita africana», la cual la inferioriza más, casi aludiendo de forma despectiva al lugar del que proviene, África. Según Johanna Jers, «el sufijo -ito/-a puede expresar, por ejemplo, superlativos, reforzar adverbios, expresar ironía y expresar una petición. [...] Aunque muestra que hay muchas funciones de -ito/-a, Beinhauer dice que la función primaria de -ito/-a es expresar pequeñez» (Beinhauer, como se cita en Jers, 2009, p. 16). En este caso, vemos que esta pequeñez está asociada a la inferioridad.

A partir del segundo personaje, se aproxima una narrativa siniestra, que causa la pequeñez e inferioridad de Flor: le causa temor al tercer personaje, una niña de cinco años; al cuarto personaje femenino, de igual forma, le causa tristeza su fotografía, "pero es una tristeza animal, no es tristeza humana» (1988, p. 76). Se refuerza la idea de que la tristeza que Flor siente no es comparable a la tristeza de una persona del mundo civilizado. Los sentimientos también son disminuidos.

El quinto personaje que lee el periódico, un niño, ve a Flor como un juguete que puede asustar a su hermano. La madre de este niño empieza a recordar eventos que una cocinera le contó, acerca de sus vivencias en el orfanato, el jugar con una niña muerta, bañarla, vestirla como si fuera su muñeca; a la vez, empieza a reflexionar: "Y considero la crueldad de la necesidad de amar. Consideró la crueldad de la necesidad de amar. Consideró la malignidad de nuestro deseo de ser feliz» (p. 77). Lo que mueve a la madre, más que el deseo de amar y de ser felices, es el deseo de dominar a alguien más pequeño, indefenso, sumiso y digno de ser dominado. «Debe ser el bebé negro más pequeño del mundo — respondió la madre, derritiéndose de gusto-. Imagínense, ella sirviendo la mesa aquí $[\ldots]$ » (p. 78). Pequeña Flor está embarazada y, a pesar de su estado, 
https://doi.org/10.46744/bapl.202002.014

no es vista con ninguna consideración por las demás mujeres, sino como una sirvienta que puede servirles. El bebé de Pequeña Flor es visto como una criatura que va a ser mucho más fácil de someter, ya que el personaje de la madre no puede contener las ansias de tenerlo para sí (derritiéndose del gusto). Es interesante notar que, para Said (2002), este fenómeno del poseedor-poseído, sociológicamente, podría analizarse como una idea que tienen los occidentales acerca de que solo los verdaderamente humanos (ellos) pueden poseer.

El consumidor occidental [...] tiene el derecho de poseer o de gastar (o de las dos cosas) la mayor parte de los recursos de la tierra. ¿Por qué?, porque él, al contrario que el oriental, es un ser humano verdadero. (2002, pp. 139-140)

Para Said, esto es «reducir a la esencia y despojar de humanidad» (p. 140) a individuos de otras culturas consideradas primitivas; incluso cuando Pequeña Flor siente un gran «amor», sus sentimientos son reducidos más a las profundidades: "Profundo amor" ya que no teniendo otros recursos, ella estaba reducida a la profundidad» (Lispector, 1988, p. 80). En palabras de Gayatri Spivak, «si es pobre, negra y mujer, la subalternidad aparece por triplicado» (1998). Pequeña Flor, sostiene la autora, representa el sujeto subalterno; su lenguaje es simple, rural, no tiene voz, y si la tiene, no es escuchada ni comprendida. El lenguaje es lo que le da poder al cazador. Por lo tanto, en «La Mujer...» se cumplen los estereotipos que los individuos de una sociedad occidental tienen respecto a ciertas narraciones sobre el continente del Tercer Mundo: el típico explorador blanco, la nativa como objeto extraño y exótico. El sujeto subalterno degenerado al máximo es representado por el hombre blanco de occidente. Sin embargo, cuando Pequeña Flor ríe, Fuentes Bayona (2015) apunta:

Con ello evidencia su naturaleza humana, pues "podría decirse que la risa, lo risible, ha estado siempre ligado a la vida del hombre, dado que uno de los rasgos que lo distingue de los demás seres vivientes...". (2015, pp. 10-11)

Sin embargo, para Lispector, la subalternidad o el sujeto dominado, no está en si tiene o no voz, sino en el hecho de poseer. Esta posesión 
está relacionada a la condición oscura del ser humano, como una especie de maldad, aquello que probablemente nos hace primitivos al igual que Pequeña Flor.

"Y una gran oscuridad se había puesto en movimiento» (Lispector, 1988 , p. 80). Esta gran oscuridad está relacionada al amor, el cual, a su vez, está vinculado a la posesión.

Pequeña Flor respondió que «sí». Que era muy lindo tener un árbol para vivir, suyo, de ella. Pues - y eso ella no lo dijo, pero sus ojos se tornaron tan oscuros que lo dijeron-. , pues era bueno poseer, era bueno poseer, era bueno poseer. (p. 81)

Pequeña Flor le da la razón a Petre respecto a que su lenguaje es simple. Este querer poseer la saca de su subalternidad y la coloca al mismo nivel de las demás mujeres que querían poseerla. Es un sentimiento universal. Sus ojos se tornan oscuros mientras desea poseer y esto es enfatizado tres veces. Sin embargo, colocarla en el discurso académico es otra forma de posicionarla al mismo nivel que otros personajes de otras literaturas.

Me tomé la libertad de citar a Said a lo largo del ensayo, ya que el orientalismo es África, Sudamérica, China, las mujeres, los vagabundos, todos aquellos por los cuales otro tiene que hablar y por donde se crea un imaginario de cómo son o cómo deben comportarse. Lispector nos deja una enseñanza: «Dios sabe lo que hace» $(1988$, p. 81$)$, es un cómo proceder eficazmente ante el «es bueno poseer». Hay que relacionarnos con el otro de una forma eficaz, dejar de mirar al «Otro» como objeto, a pesar de los estereotipos o generalizaciones que se han llevado a cabo a lo largo de los siglos por sujetos e instituciones, pero avalados por los propios individuos dominados, las mujeres que veían a Pequeña Flor como lo «Otro». 
https://doi.org/10.46744/bapl.202002.014

\section{BIBLIOGRAFÍA}

BEEGHLY, E. (2015). What is a Stereotype? Hypatia, 30(4). Recuperado de http://eds.b.ebscohost.com/eds/pdfviewer/ pdfviewer?vid =1\&sid=e2f30afc-3579-44f0-bcdfe56c22f9f $724 \% 40$ sessionmgr102\&hid $=122$

CARRERA, E. (1999). The reception of Clarice Lispector via Helen Cixous: Reading from the Whale's Belly. Brazilian Feminisms, pp. 85-100. Nottingham: University of Nottingham Press. Recuperado de https://core.ac.uk/download/pdf/17537.pdf.

CHEVALIER, J. y GHEERBRANT, A. (1986). Diccionario de simbolos. Barcelona: Herder.

FUENTES BAYONA, A. (2015). La configuración del amor en La mujer más pequeña del mundo de Clarice Lispector. Recuperado de https://www.researchgate.net/publication/276026128 La_configuracion_del_amor_en_La_mujer_mas_pequena_ del_mundo_de_Clarice_Lispector

FRANCO, J. (2003). Decadencia y caída de la ciudad letrada. La literatura latinoamericana durante la guerra fría. Madrid: Debate.

JERS, J. (2009). Las funciones del sufijo diminutivo Un estudio sobre su uso en Manolito Gafotas. Lunds Universitet. Recuperado de http:// lup.lub.lu.se/luur/download?func $=$ downloadFile\&recordO $\mathrm{Id}=1716302 \&$ fileOId $=1716303$

LAMAS, M. (1999). Usos, dificultades y posibilidades de la categoría género.Papeles de Población, 5(21), pp. 147-178. Recuperado de http://www.redalyc.org/pdf/112/11202105.pdf

LISPECTOR, C. (1988). La mujer más pequeña del mundo. Lazos de familia. Barcelona: Montesinos Editor. 
https://doi.org/10.46744/bapl.202002.014

SAID, E. (2002). Orientalismo. Traducción de María Luisa Fuentes. Barcelona: Debolsillo.

SPIVAK, G. (1998). ¿Puede el sujeto subalterno hablar? Orbis Tertius, 3(6), pp. 175-235. Recuperado de http://www.memoria.fahce. unlp.edu.ar/art_revistas/pr.2732/pr.2732.pdf 